\title{
ROLE OF THE SPLEEN ON THE PATHOGENESIS OF SCHISTOSOMAL PERIPORTAL (PIPESTEM) FIBROSIS OF THE LIVER: AN EXPERIMENTAL APPROACH
}

\author{
ZILTON A. ANDRADE, LUCIANA M. SILVA, MARCIA MARIA DE SOUZA, MOYSÉS SADIGURSKY, \\ ARYON BARBOSA JR, AND IRISMAR REIS DE OLIVEIRA \\ Laboratory of Experimental Pathology, Gonçalo Moniz Research Center (FIOCRUZ) Salvador, Bahia, Brazil
}

\begin{abstract}
Splenectomized and sham-operated mice with chronic Schistosoma mansoni infection were compared for the development of periportal fibrosis (pipestem fibrosis). Although this lesion appeared less frequently in splenectomized mice, it also developed in the absence of the spleen. The time of splenectomy, spleen weight, presence of anti-idiotypic antibodies, the number of eggs in the liver, and the type and size of periovular granulomas in the liver as evaluated by computerized morphometry did not show statistically significant differences between the two groups. It is concluded that the role of the spleen in the development of pipestem fibrosis seems ancillary and that multifactorial influences, including worm burden, hepatic vascular adjustment, and factors associated with the biology of extracellular matrix of the liver, probably play a more significant role.
\end{abstract}

Hepatic periportal fibrosis is the most important and characteristic anatomic finding in hepatosplenic schistosomias. This lesion has been known as pipestem fibrosis since Symmers first described it in $1904 .{ }^{1}$ Although high worm load is considered the major factor in its pathogenesis, ${ }^{2,3}$ additional factors probably play an important role since not all severely infected people will develop hepatosplenic disease. Only 4$12 \%$ of those infected and living in areas of high endemicity are expected to develop periportal fibrosis, with its accompanying features of intrahepatic portal vein obstruction, portal hypertension, and hepatosplenomegaly, so-called hepatosplenic disease. ${ }^{4}$ Variations in percentages are considered to reflect the degree of transmissibility in a particular geographic area. ${ }^{3}$

Several cofactors have been suggested to be important. These include the role of repeated infections as opposed to a single or few exposures, the age and race of the patients, their blood groups, duration of infection, failure of immunologic modulation, and HLA determinants. ${ }^{5-8}$ The evidence for and against each one of these cofactors is meager and the problem has remained complex and is difficult to solve with materials from human patients. Therefore, the need for an experimental model is crucial.

Although a gross and microscopic picture of pipestem fibrosis has been obtained in chimpanzees heavily infected with Schistosoma mansoni, ${ }^{9}$ the primate model is obviously not adequate for practical use. However, mice with prolonged (16 weeks or more) and relatively mild (1-2 worm pairs) can develop periportal fibrosis that mimics the human lesion. ${ }^{10}$ Periportal fibrosis appears only in a certain percentage of chronically infected mice, even when inbred animals are used, indicating that other factors, besides worm burden, time, and to a certain extent, genetic background, are also involved. ${ }^{11}$

By using male CBA/J mice with chronic S. mansoni infection, Henderson and others ${ }^{12}$ have shown that mice developing diffuse periportal fibrosis also exhibited massive splenomegaly and immunologic abnormalities in the generation of modulatory anti-idiotypic antibodies. Although the splenomegaly found was of a lymphoproliferative type rather than a congestive one, the general experimental findings closely resembled the changes seen in human pathology. ${ }^{13}$ Therefore, the pathogenesis of schistosomal pipestem fibrosis may also be influenced by changes in the spleen.
In the present study, we used the mouse model of pipestem fibrosis to investigate the role of the spleen on the pathogenesis of schistosomal periportal fibrosis by observing how that lesion would develop in splenectomized animals.

\section{MATERIALS AND METHODS}

Animals and surgical procedures. One-hundred outbred Swiss mice of both sexes weighing 18-20 g and maintained on a balanced commercial diet were used. Splenectomy was performed under sterile conditions with ether anesthesia. A small incision was made on the shaved skin of the superior lateral flank, the muscle layer was dissociated, the spleen was removed and weighted, and the wound was sutured. Fragments of the spleen were immediately fixed in Bouin's fluid for $6 \mathrm{hr}$, washed in 70\% ethanol, and embedded in paraffin. Surgery was performed with minimal or no bleeding and there was no mortality. Sham-operated animals underwent the same surgical procedures, with the spleen being exteriorized and manipulated, but not removed.

Infection. Mice were infected by the transcutaneous route with 30 recently shed $S$. mansoni cercariae per mouse. Animals were individually infected inside a clean small bottle after a warm bath to rid them of feces and urine. All animals included in this study passed viable schistosome eggs in their stools 35-45 days following exposure.

Groups. The following experimental groups, each with 20 animals, were used. They differed according to the time of splenectomy. Group 1 was splenectomized one week before infection. Groups 2, 3, and 4 consisted of animals splenectomized one week, four weeks, and eight weeks, respectively, after cercarial exposure. A fifth group, a control group, consisted of sham-operated animals. Surgery in the control group was performed one week before infection with $S$. mansoni cercariae.

Killing and post-mortem procedures. Animals were killed on two occasions: one-third of the animals were killed 12 weeks after infection and the others after 17 weeks. Under ether anesthesia, the animals were exsanguinated by severing the brachial plexus, from which blood was collected for immunologic studies. After coagulation and centrifugation of the blood, sera were stored at $4^{\circ} \mathrm{C}$. Recovering of worms was done using the Duvall and DeWitt ${ }^{14}$ method of perfusion. Counting of schistosome eggs was done after di- 
TABLE 1

Development of pipestem fibrosis in mice chronically infected with Schistosoma mansoni, with and without splenectomy*

\begin{tabular}{|c|c|c|c|}
\hline \multirow[b]{2}{*}{ Splenectomy } & \multicolumn{2}{|c|}{ Pipestem fibrosis } & \multirow[b]{2}{*}{ No. of animals } \\
\hline & Yes & No & \\
\hline Yes & $15(25.0 \%)$ & $45(75.0 \%)$ & 60 \\
\hline No & $21(61.8 \%)$ & $13(38.2 \%)$ & 34 \\
\hline Total & $36(38.3 \%)$ & $58(61.7 \%)$ & 94 \\
\hline
\end{tabular}

$* \chi^{2}=10.9$, degrees of freedom $=1, P<0.05$.

gestion with potassium hydroxide, according to the method of Cheever. ${ }^{15}$

Fragments of the liver were fixed in Bouin's fluid and embedded in paraffin. Histologic sections of the spleen and liver were stained with hematoxylin and eosin, and siriusred for collagen. ${ }^{16}$ Spleen removed one week before infection were also microscopically examined and taken as representative of noninfected controls.

Immunology. Schistosoma mansoni antigen was obtained from adult worms. Serum antibodies against $S$. mansoni, as well as anti-idiotypic antibodies, were measured by an ELISA method. Samples were always analyzed in duplicate. Anti-idiotypic antibodies were detected using the technique described by Sadigursky and others. ${ }^{17}$ Briefly, $\mathrm{F}\left(\mathrm{ab}^{\prime}\right)_{2}$ fragments specific for $S$. mansoni were obtained from monospecific IgG by pepsin digestion and further purification on a Sephadex A-160 column. The IgG solution was adjusted to a concentration of $20 \mathrm{mg} / \mathrm{ml}$ and dialyzed against $0.1 \mathrm{M}$ sodium acetate for $3 \mathrm{hr}$. The $\mathrm{pH}$ of the dialysate was to 4.5 with acetic acid, and $2 \mathrm{mg}$ of pepsin was added to each 100 $\mathrm{mg}$ of IgG. After incubation for $12 \mathrm{hr}$ at $37^{\circ} \mathrm{C}$ and centrifugation for $30 \mathrm{~min}$ at $4,000 \times g$, the supernatant was collected, adjusted to a $\mathrm{pH}$ of 7.4 , and dialyzed against phos- phate-buffered saline. The solution was then purified through a G-100 Sephadex column. The $S$. mansoni unrelated $\mathrm{F}\left(\mathrm{ab}^{\prime}\right)_{2}$ fragments were similarly prepared from sera of noninfected mice. Control $\mathrm{F}\left(\mathrm{ab}^{\prime}\right)_{2}$ fragments were obtained from a pool of noninfected mice sera.

Morphometric data. Randomly sampled $5 \mu$-thick histologic sections stained with picro-sirius-red for collagen were examined by semi-automatic morphometry using the Leica Q500MC Image Processing and Analysis System (Leica, Cambridge, United Kingdom). For morphometric measurements, a total sectional area of $1.64 \mathrm{~mm}^{2}$ per animal was evaluated. All periovular granulomas were included. A spherical shape and normal size distribution were assumed. The following granuloma parameters were calculated: size (sectional area), granuloma volume, volume density, and numerical density. Volume density refers to the space (volume) occupied by the granulomas in the compartment of the liver tissue examined. Numerical density indicates the number of granulomas per unit of tissue considered $\left(\mathrm{mm}^{3}\right)$.

The granuloma volume density was calculated as the quotient of the total granuloma profile area to the total sectional area studied per animal. The number of granulomas per unit volume of liver was assessed by applying the formula of Weibel. ${ }^{18}$ The sectional area of the red-stained fibrous tissue was directly measured and calculated as a percent of the total area examined. The mean granuloma volume was estimated according to the method of Bertran. ${ }^{19}$ The relation of total collagen/granuloma was not measured.

Statistical analysis. Categorical data were compared by using the chi-square test with a Yates' correction. Student's $t$-test was used to compare continuos variables, which are presented as means \pm SD. Statistical significance was defined by a $P$ value $<0.05$. For the morphometric data, a two-way analysis of variance test was applied.

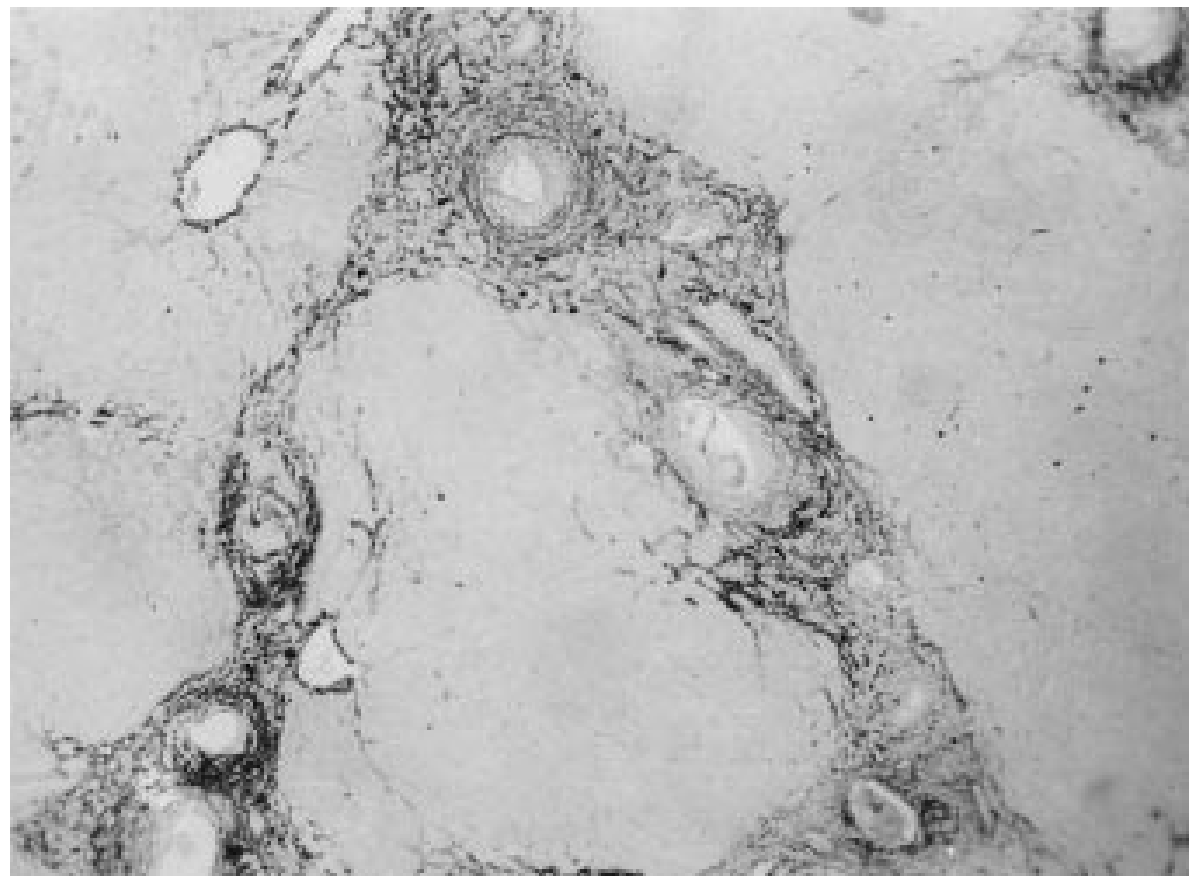

FIGURE 1. Microscopic representation of the murine model of pipestem fibrosis. Periovular granulomas are shown associated with collagen fibers form bands of fibrous tissue along the periportal spaces, connecting one portal space to the other, against a background of unstained hepatic parenchyma, which maintains its normal lobular architecture (picro-sirius-red method for collagen, magnification $\times 100$ ). 


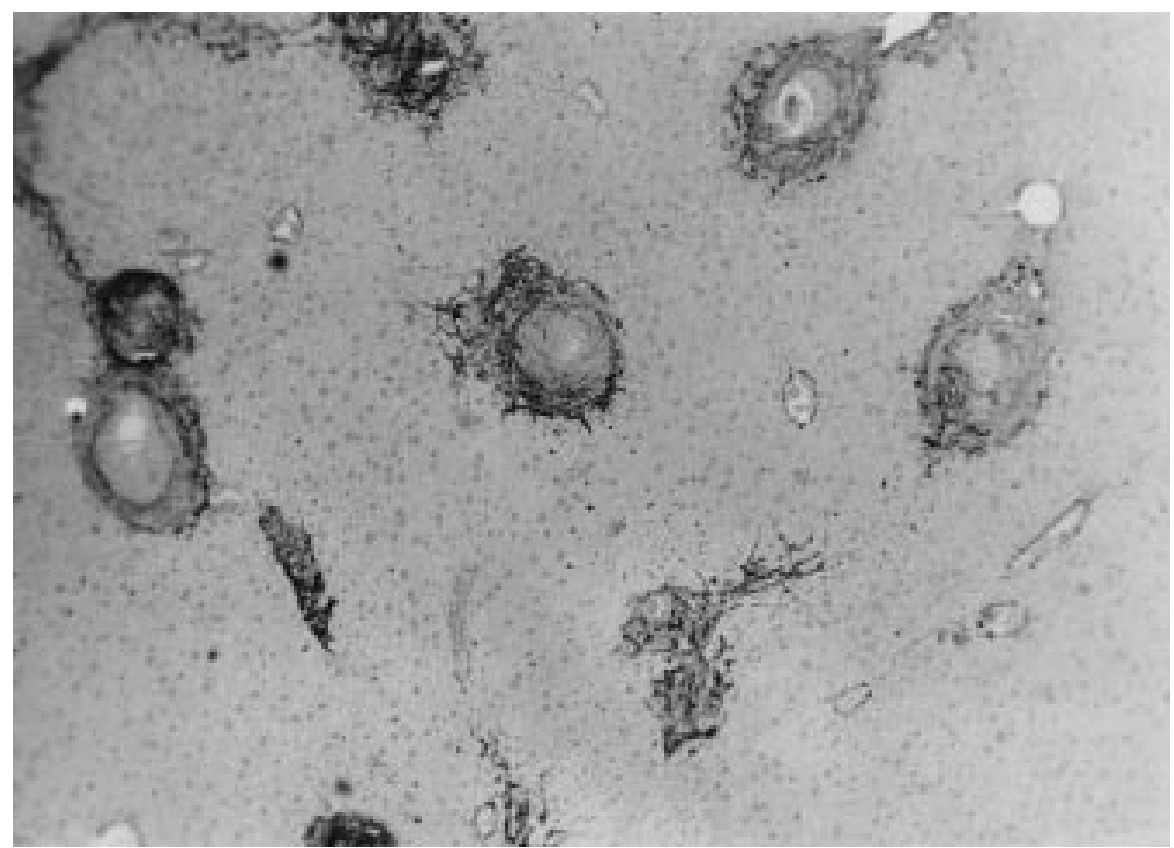

FIGURE 2. Isolated periovular granulomas in the liver of a mouse. This represents the type of lesion seen in mice that failed to develop pipestem fibrosis after a prolonged and relatively mild schistosomal infection (picro-sirius-red method for collagen, magnification $\times 100$ ).

\section{RESULTS}

Since the results obtained from the animals killed 12 and 17 weeks after infection were similar, they are described together. An average of 1-2 worm pairs was recovered from infected mice. Four animals were not infected or were infected with male worms only. They were discarded. The number of eggs in the liver was expressed as per gram of liver tissue and varied from 6,400 to 10,300 in the groups, but such variation did not show any statistically significant difference.

Histologic examination of the liver in 94 mice with prolonged schistosomal infection revealed that pipestem fibrosis was present in $38.3 \%$. Table 1 shows the distribution of the lesion in splenectomized and sham-operated animals. Splenectomized animals were less prone to develop systematized periportal granulomas and fibrosis $(P<0.001)$.

Pipestem fibrosis was characterized by a preferential accumulation of schistosome eggs and the granulomas they elicited along periportal areas, forming bands of fibrosis that extended between portal spaces and made septal connections on a background of normal-looking parenchyma (Figure 1). The cases without such lesions exhibited isolated periovular granulomas that were sparsely distributed throughout the liv-

TABLE 2

Development of pipestem fibrosis in splenectomized mice chronically infected with Schistosoma mansoni, in relation to the time of splenectomy*

\begin{tabular}{lccl}
\hline \multirow{2}{*}{$\begin{array}{c}\text { Splenectomy time in } \\
\text { relation to time of } \\
\text { infection }\end{array}$} & \multicolumn{3}{c}{ Pipestem fibrosis } \\
\cline { 2 - 4 } & $6(20.0 \%)$ & $24(80.0 \%)$ & 30 \\
\hline One week before & $9(30.0 \%)$ & $21(70.0 \%)$ & 30 \\
$1-8$ weeks after & $15(25.0 \%)$ & $45(75.0 \%)$ & $60(100.0 \%)$ \\
Total &
\end{tabular}

$* \chi^{2}=0.36$, degrees of freedom $=1, P>0.05$. er tissue (Figure 2). Differentiation between the two types of lesions was easily accomplished when the sirius-redstained slides were examined by low-power microscopy. However, in four instances the lesion was difficult to classify since many isolated granulomas appeared in a liver that also showed a concentration of periportal granulomas in a few areas. These mixed cases were finally considered as without pipestem fibrosis. In sections stained with sirius-red, collagen sometimes exhibited focal areas of fragmentation, thickening, tortuosities, and disappearance of the fibers. These foci of collagen degradation were seen more frequently and more accentuated in nonsplenectomized animals.

The distribution of the two types of hepatic lesions in relation to the time of splenectomy is depicted in Table 2. No significant difference in the development of periportal fibrosis was seen regarding the time of splenectomy. Table 2 also contains data on number of eggs per gram of liver, but no special significance was apparent in relation to this parameter and the tendency to develop pipestem fibrosis.

Table 3 shows the problem of spleen weight in the group of sham-operated animals with and without pipestem fibrosis. Again, there was no relationship $(P>0.05)$ between spleen weight and the development of the characteristic periportal lesion.

Histologic examination of the spleen showed that the gen-

TABLE 3

Spleen weight (grams) of mice chronically infected with Schistosoma mansoni, subjected to sham-splenectomy, in relation to the groups with and without pipestem fibrosis (PF)*

\begin{tabular}{lcc}
\hline \multicolumn{1}{c}{ Groups } & No. of animals & $\begin{array}{l}\text { Spleen weight } \\
(\text { mean } \pm \text { SD) }\end{array}$ \\
\hline With PF & 17 & $0.2802 \pm 0.151$ \\
Without PF & 12 & $0.2369 \pm 0.092$ \\
\hline
\end{tabular}

$* \mathrm{t}=0.88$, degrees of freedom $=27, P>0.05$ 
TABLE 4

Mean \pm SD titers of idiotypic (ID) and anti-idiotypic serum antibodies in mice chronically infected with Schistosoma mansoni, with and without pipestem fibrosis (PF) of the liver

\begin{tabular}{|c|c|c|c|}
\hline \multirow[b]{2}{*}{ Groups } & \multicolumn{3}{|c|}{ Serum antibodies } \\
\hline & Anti-S. mansoni & Anti-ID $S$. mansoni & Anti-ID nonrelated antigen \\
\hline With PF & $\begin{array}{c}185.7143 \pm 37.79^{*} \\
\mathrm{n}=7\end{array}$ & $\begin{array}{c}71.66 \pm 11.96 \dagger \\
\mathrm{n}=9\end{array}$ & $\begin{array}{c}34.20 \pm 15.36 \neq \\
\mathrm{n}=10\end{array}$ \\
\hline Without PF & $\begin{array}{c}152.00 \pm 50.99 * \\
\mathrm{n}=25\end{array}$ & $\begin{array}{c}75.14 \pm 11.86 \dagger \\
\mathrm{n}=23\end{array}$ & $\begin{array}{c}41.16 \pm 14.61 \% \\
n=25\end{array}$ \\
\hline
\end{tabular}

$* \mathrm{t}=1.62$, degrees of freedom $(\mathrm{df})=30 ; P=0.12$.

$\dagger \mathrm{t}=0.74, \mathrm{df}=30, P=0.46$

$\ddagger \mathrm{t}=1.26, \mathrm{df}=33, P=0.22$

eral normal architecture of the organ was generally maintained. There was a variable degree of red pulp congestion. Foci of proliferation of lymphocytes, with admixture of many plasmocytoid cells and eosinophils, were seen, especially at the red pulp and marginal zones. Lymph follicles varied from atrophic to hyperplastic. However, although these changes were much more prominent in the infected groups than in noninfected controls, no consistent pattern of changes could be correlated with any of the two main experimental groups studied. Secondary-type amyloidosis, involving the spleen, liver, and kidneys, was found in four mice with chronic $S$. mansoni infection, none of them splenectomized.

The search for anti-schistosome and anti-idiotype antibodies also failed to discriminate among the several groups of mice. Results are shown in Table 4.

Morphometric analysis showed no significant differences between the groups regarding sectional area, volume, and volumetric and numerical densities of the periovular granulomas in the liver (Table 5). Hepatic fibrosis was greater in the animals developing periportal fibrosis as compared with those with scattered hepatic granulomas when measured morphometrically in total amount or as a percent of hepatic tissue.

\section{DISCUSSION}

Changes in the liver (venous congestion, inflammation, fibrosis, necrosis) can have repercussions on splenic structure and function, but there are suggestions that the reciprocal may also occur. In so-called Banti's syndrome, it has been postulated that primary splenomegaly may be sequentially followed by portal hypertension, liver fibrosis, and even cirrhosis. ${ }^{20}$ Splenectomy performed in patients with hepatosplenic schistosomiasis ameliorated the humoral im- mune response and increased the CD4:CD8 lymphocyte ratio. ${ }^{21}$ Experimentally, splenectomy failed to modify the size and type of periovular granulomas in the liver, except when performed on the eighth week of infection, when the reaction around the eggs was enhanced in splenectomized mice. ${ }^{22,23}$

Under the present experimental conditions, the presence of the spleen seemed important, but not essential, for the development of periportal hepatic fibrosis (pipestem fibrosis) in mice chronically infected with $S$. mansoni. A statistically significant proportion of the cases occurred in nonsplenectomized animals compared with those that were splenectomized. The reason for this is not clear. Time of splenectomy, whether before infection or afterwards, did not have a significant influence on the development of the lesion. However, no clear-cut differences were seen between splenectomized and nonsplenectomized animals concerning levels of serum antibodies against $S$. mansoni, anti-idiotypic antibodies tested against whole worm antigens, the size of the spleen (splenic index), or intensity of infection (recovery of worms and counting of eggs per gram of liver tissue). No evidence for the role of anti-idiotypic antibodies was found. The antigen used here (whole worm antigen) differed from that used by Henderson and others, ${ }^{12}$ which consisted of egg antigen. However, since the effect of anti-idiotypic antibodies would be on granuloma modulation, our morphometric data did not indicate differences between splenectomized and sham-operated animals, or between animals presenting with periportal fibrosis compared with those with isolated granulomas. In addition, our monospecific antibodies obtained from male and female adult worms strongly reacted with egg antigens.

All of our infected animals can be considered as presenting high worm loads. It has been estimated that the heaviest infection occurring in a $60-\mathrm{kg}$ human is seldom greater than

TABLE 5

Morphometric measurements (mean $\pm \mathrm{SD}$ ) of periovular granulomas in the livers of mice with and without schistosomal pipestem fibrosis $(\mathrm{PF})$ either splenectomized or sham-operated*

\begin{tabular}{lcccc}
\hline \multicolumn{1}{c}{ Groups $\dagger$} & \multicolumn{1}{c}{$\begin{array}{c}\text { Sectional } \\
\text { area }\left(\mu \mathrm{m}^{2}\right)\end{array}$} & $\begin{array}{c}\text { Volume } \\
\left(\mu \mathrm{m}^{3}\right)\end{array}$ & Volume density & $\begin{array}{c}\text { Numerical } \\
\text { density }\end{array}$ \\
\hline Splenectomy & & & & \\
PF+ & $6,350 \pm 267$ & $273,700 \pm 86,400$ & $0.07638 \pm 0.008$ & $279 \pm 96$ \\
PF- & $5,639 \pm 637$ & $255,500 \pm 25,900$ & $0.08330 \pm 0.023$ & $326 \pm 96$ \\
Sham-operated & $5,386 \pm 564$ & $104,100 \pm 70,800$ & $0.05144 \pm 0.028$ & $494 \pm 401$ \\
PF+ & $6,257 \pm 3,102$ & $250,700 \pm 144,600$ & $0.06018 \pm 0.012$ & $240 \pm 80$ \\
PF- & &
\end{tabular}

$* P>0.05$, by two-way analysis of variance regarding sectional area, volume, volume density, and numerical density taking splenectomy/sham-operation and $\mathrm{PF}+/ \mathrm{PF}-$ as factors. $\dagger$ Four animals in each subgroup. 
five worm pairs, whereas in a 20 -g mouse, the lightest infection is of the order of 50 worm pairs. ${ }^{24}$

There are controversies about accepting the mouse model as representative of the condition seen in human pathology. ${ }^{25}$ A critical appraisal of the murine model of pipestem fibrosis has already been presented. ${ }^{11}$ The model has similarities as well as differences with human pipestem fibrosis. However, by showing fibrosis and preferential distribution of schistosome eggs along the periportal spaces, the model does reproduce the main pathogenic feature of pipestem fibrosis.

Present findings do not support previous suggestions about the pathogenesis of pipestem fibrosis, but serve to point toward other directions that have apparently been neglected. One of them is the process of intrahepatic vascular adjustment to the continuous arrival of parasite eggs.

In both humans ${ }^{26,27}$ and mice ${ }^{28}$ with pipestem fibrosis, a cuffing of fine anastomosed portal vessels is formed around and along the intrahepatic portal vein branches. Changes in the spleen may have an influence on these vascular dynamic processes, since splenomegaly contributes more blood and higher pressure to the portal system. ${ }^{20,29,30}$

The pathogenetic importance of a similar set of vascular events has been previously demonstrated for the pulmonary changes seen in advanced schistosomiasis, the so-called schistosomal cor pulmonale. ${ }^{31}$ This complication occurred in $17 \%$ of hepatosplenic patients, apparently with no peculiar differences, immunologic or otherwise, between them and others who did not develop this complication. The same is probably true for the liver. Besides the fundamental contribution of heavy worm load, factors influencing crucial vascular changes in the liver during the course of severe schistosomiasis seem to be important. These factors are probably multifactorial. Immunologic factors, ${ }^{7}$ cytokines, ${ }^{32}$ and the host capacity to form and to degrade extracellular matrix ${ }^{33,34}$ might also play a role in the pathogenesis of schistosomal periportal fibrosis.

Financial support: This work was supported by PAPES I (Oswaldo Cruz Foundation) and PRONEX.

Authors' address: Zilton A. Andrade, Luciana M. Silva, Marcia Maria de Souza, Moysés Sadigursky, Aryon Barbosa, Jr, and Irismar Reis de Oliveira, Laboratory of Experimental Pathology, Gonçalo Moniz Research Center (FIOCRUZ) Salvador, Bahia, Brazil.

\section{REFERENCES}

1. Symmers WStC, 1904. Note on a new form of liver cirrhosis due to the presence of the ova of Bilharzia haematobia. $J$ Pathol Bacteriol 9: 237-239.

2. Cheever AW, 1968. A quantitative post-mortem study of schistosomiasis mansoni in man. Am J Trop Med Hyg 17: 38-64.

3. Coura JR, Conceição MJ, 1981. Correlação entre carga parasitária do $S$. mansoni e gravidade das formas clínicas em uma comunidade rural de Minas Gerais. Rev Soc Bras Med Trop 14: 93-97.

4. Chen MG, Mott KE, 1988. Progress in assessment of morbidity due to Schistosoma mansoni infection. A review of recent literature. Trop Dis Bull 85: 1-56.

5. Tavares-Neto J, Prata A, 1989. Family occurrence of schistosomal splenomegaly and maternal effects. Rev Soc Bras Med Trop 22: 13-18.

6. Pereira FEL, Bortolini ER, Carneiro JLA, Silva CRM, Neves $\mathrm{RC}$, 1979. ABO blood groups and hepatosplenic form of schistosomiasis mansoni (Symmers' fibrosis). Trans $R$ Soc Trop Med Hyg 73: 238-242.

7. Colley DG, Garcia AA, Lambertucci JR, Parra JC, Katz N, Rocha RS, Gazzinelli G, 1986. Immune responses during human schistosomiasis. XII. Differential responsiveness in patients with hepatosplenic disease. Am J Trop Med Hyg 35: 793802.

8. Prata A, 1991. Fatores determinantes das formas anátomo-clínicas e evolução da esquistossomose. Castro FP, Rocha PRS, Cunha AS, eds. Tópicos em Gastroenterologia. Rio de Janeiro: MEDSI-Editora Médica e Científica Ltda, 3-12.

9. Sadun EH, Lichtenber F, Cheever AW, Erickson DG, 1970. Schistosomiais mansoni in the chimpanzee. The natural history of chronic infections after single and multiple exposures. Am J Trop Med Hyg 19: 258-277.

10. Warren KS, 1966. The pathogenesis of "clay-pipe stem cirrhosis" in mice with chronic schistosomiasis mansoni, with a note on the longevity of the schistosomes. Am J Pathol 49: 477-489.

11. Andrade ZA, Cheever AW, 1993. Characterization of the murine model of schistosomal hepatic periportal fibrosis ("pipestem" fibrosis). Int J Exp Pathol 74: 195-202.

12. Henderson GS, Nix NA, Montesano A, Gold G, Freeman Jr GL, McCurley T, Colley DG, 1993. Two distinct pathological syndromes in male CBA/J inbred mice with chronic Schistosoma mansoni infections. Am J Pathol 142: 703-714.

13. Cheever AW, 1993. Schistosomiasis: infection versus disease and hypersensitivity versus immunity. Am J Pathol 142: 699702.

14. Duvall RH, DeWitt W, 1969. An improved perfusion technique for recovering adult schistosomes from laboratory animals. Am J Trop Med Hyg 16: 483-486.

15. Cheever AW, 1970. Relative resistance of the eggs of human schistosomes to digestion in potassium hydroxide. Bull World Health Organ 43: 601-603.

16. Junqueira LCU, Bignolas G, Brentani R, 1979. Picrosirius staining plus polarization microscopy, a specific method for collagen detection in tissue sections. Histochem J 11: 447-455.

17. Sadigursky, M, von Kreuter, B, Ling, PY, Santos-Buch, CA, 1989. Association of elevated anti-sarcolemma antio-idiotype antibody levels with the clinical and pathological expression of chronic Chagas' myocarditis. Circulation 80: 1269-1276.

18. Weibel E, 1969. Stereological principles for morphometry in electron microscopic cytology. Int Rev Cytol 26: 235-302.

19. Bertram JF, 1995. Analyzing renal glomeruli with the new stereology. Int Rev Cytol 161: 111-172.

20. Yamamoto K, 1979. Morphological study of the spleen in idiopathic portal hypertension (so called Banti's syndrome without cirrhosis) using light microscopy, scanning electron microscopy and histometry. Acta Pathol Jpn 29: 1-19.

21. Khalil HM, Missiry AG, Fikry AA, Khalil NM, Sedky Há, 1991. Effect of splenectomy on cell-mediated immunity in bilharzial patients with splenomegaly. J Egypt Soc Parasitol 21: 91-98.

22. Hood AT, Boros DL, 1980. The effect of splenectomy on the pathophysiology and egg-specific immune response of Schistosoma mansoni-infected mice. Am J Trop Med Hyg 29: 586591.

23. Arruda SM, Santoro F, Sadigursky M, 1993. Evaluation of spleen cell population and effect of splenectomy on granuloma modulation in BALB/c mice infected with Schistosoma mansoni. Mem Inst Oswaldo Cruz 88: 97-102.

24. Cheever AW, 1969. Quantitative comparison of the intensity of Schistosoma mansoni infections in man and experimental animals. Trans $R$ Soc Trop Med Hyg 63: 781-795.

25. Cheever AW, 1965. Comparative study of Schistosoma mansoni infections in mice, gerbils, multimammate rats and hamsters. II. Qualitative pathological differences. Am J Trop Med Hyg 14: 227-238.

26. Bogliolo L, 1957. The anatomic picture of the liver in hepatosplenic schistosomiasis mansoni. Ann Trop Med Parasitol 51: $1-14$.

27. Andrade ZA, Cheever AW, 1971. Alterations of the intrahepatic 
vasculature in hepatosplenic schistosomiasis mansoni. Am J Trop Med Hyg 20: 425-432.

28. Andrade ZA, 1987. Pathogenesis of pipe-stem fibrosis of the liver (experimental observation on murine schistosomiasis). Mem Inst Oswaldo Cruz 82: 325-334.

29. Andrade ZA, Andrade SG, 1965. Patologia do baço na esquistossomose hepatesplênica. Rev Inst Med Trop Sao Paulo 7: 218-227.

30. Bishop MB, Lensing LS, 1982. The spleen: a correlative overview of normal and pathological anatomy. Hum Pathol 13: 334-342.
31. Andrade ZA, Andrade SG, 1970. Pathogenesis of pulmonary schistosomiasis. Am J Trop Med Hyg 19: 305-310.

32. Cheever AW, Xu Y, Macedonia JG, Cox T, Hieny S, Sher A, 1992. The role of cytokines in the pathogenesis of hepatic granulomatous disease in Schistosoma mansoni infected mice. Mem Inst Oswaldo Cruz 87(suppl IV): 81-85.

33. Prakash S, Postelethwaite AE, Wyler D, 1991. Alterations in influence of granuloma-derived cytokines on fibrogenesis in the course of murine Schistosoma mansoni infection. Hepatology 13: 970-976.

34. Andrade ZA, 1994. Extracellular matrix degradation in parasitic diseases. Braz J Med Biol Res 27: 2273-2281. 